\title{
Study of the Terms and Conditions of Takeover the Combined Process of Casting and Continuous Pressing Method CONFORM
}

\author{
Dmitry V. Bogdanov, \\ Sergey V. Belyaev*, Yury V. Gorokhov, \\ Ivan Y. Gubanov and Oleg O. Vinogradov \\ Siberian Federal University \\ 79 Svobodny, Krasnoyarsk, 660041, Russia
}

Received 12.02.2015, received in revised form 09.04.2015, accepted 16.05.2015

The paper presents an analysis of the conditions of capture deformable metal tool for the combined process of casting and continuous extrusion method conform depending on the design and process parameters.

Keywords: combined casting process and the continuous extrusion method conform, capture angle, friction coefficient.

DOI: $10.17516 / 1999-494 X-2015-8-5-576-581$.

\section{Исследование условий захвата \\ совмещенного процесса литья \\ и непрерывного прессования методом conform}

\section{Д.В. Богданов, С.В. Беляев, Ю.В. Горохов, И.Ю. Губанов, О.О. Виноградов Сибирский федеральный университет Россия, 660041, Красноярск, пр. Свободный, 79}

В статье представлен анализ условий захвата деформируемого металла инструментом для совмещенного процесса литья и непрерывного прессования методом сопform в зависимости от конструктивных и технологических параметров.

Ключевые слова: совмещенный процесс литья и непрерывного прессования методом сопform, угол захвата, коэффициент трения.

(c) Siberian Federal University. All rights reserved

* Corresponding author E-mail address: 244812@mail.ru 


\section{Введение}

Совмещенный процесс литья и непрерывного прессования методом conform (далее СЛиК) является одним из эффективных методов изготовления длинномерных полуфабрикатов в виде катанки, прутков или проволоки с относительно небольшим поперечным сечением из алюминиевых сплавов [1]. Для исследования данного процесса учеными СФУ в ходе выполнения научно-исследовательских работ при финансовой поддержке КГАУ «Красноярский краевой фонд поддержки научной и научно-технической деятельности» в рамках проекта «Разработка инновационной технологии литья - непрерывного прессования сварочной проволоки из алюминиевых сплавов для изготовления волноводов космической техники» была изготовлена лабораторная установка, схема которой представлена на рис. 1, а общий вид показан на рис. 2.

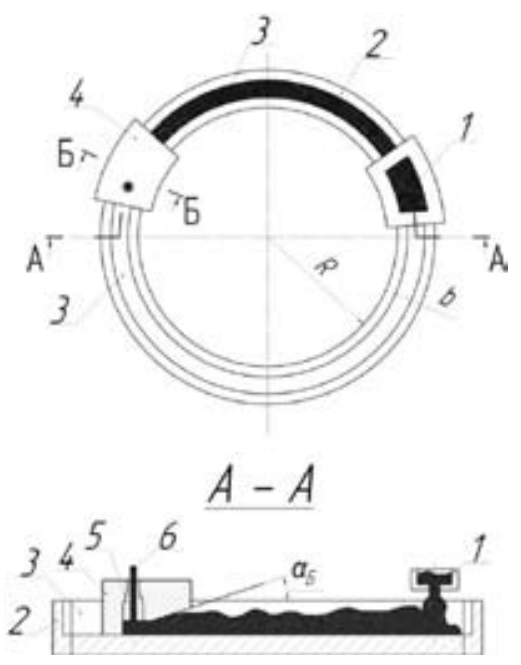

Рис. 1. Схема установки СЛиК: 1 - печь-миксер с дозатором; 2 - кристаллизатор; 3 - кольцевая канавка; 4 - неподвижный дугообразный сегмент (башмак); 5 - пресс-матрица; 6 - пресс-изделие [2]

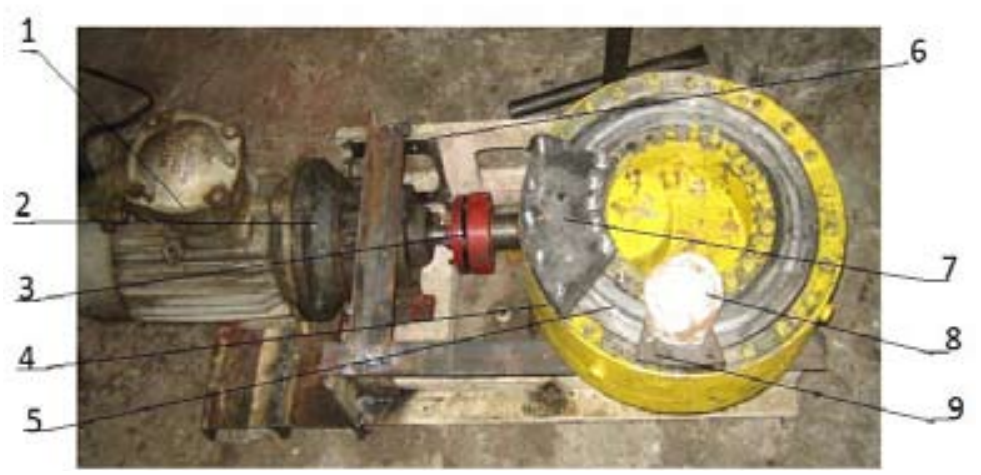

Рис. 2. Общий вид установки СЛиК: 1 - электродвигатель переменного тока; 2 - редуктор; 3 - соединительная муфта; 4 - корпус установки; 5 - кристаллизатор, прикрепленный к корпусу болтами; 6 - рама; 7 - башмак с матрицей; 8 - заливная воронка; 9 - дозатор 


\section{Анализ условий захвата при СЛиК}

В общем случае процесс совмещенного процесса литья и прессования методом conform цветных металлов и сплавов включает следующие основные этапы:

1) заливка расплавленного металла в канавку карусельного кристаллизатора;

2) охлаждение расплавленного металла в канавке до требуемой температуры деформации;

3) деформирование металла методом conform (рис. 1).

Каждый из этапов характеризуется как основными, так и второстепенными технологическими условиями, которые в совокупности должны обеспечить достижение основной цели получение продукции надлежащего качества с максимальной эффективностью.

Выбор рациональных технологических и конструктивных параметров для первых двух этапов основан на исследовании тепловых условий процесса СЛиК, а на завершающем этапе значительную роль играют энергосиловые условия процесса, особенно на начальной стадии деформирования металла методом conform.

Процесс захвата, как и последующее деформирование металла методом conform, обеспечивается наличием активных сил трения, действующих на границе контакта канавки карусельного кристаллизатора и деформируемого металла. Процесс захвата металла при conform является неустановившемся процессом, так как геометрические, кинематические и силовые параметры при деформировании металла по мере его продвижения относительно неподвижного башмака изменяются во времени. Процесс захвата металла условно можно разбить на три периода:

- момент соприкосновения деформируемого металла с башмаком (рис. 3), когда действуют только упругие деформации;

- начало захвата деформируемого металла башмаком соответствует времени, когда происходит смятие кромок заготовки, т.е. начинается пластическая деформация на границе контакта;

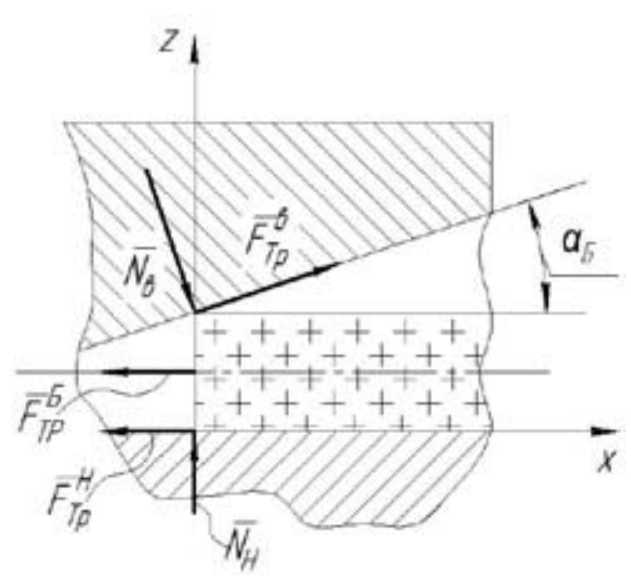

Рис. 3а. Силы, действующие на деформируемый металл в плоскости z0x

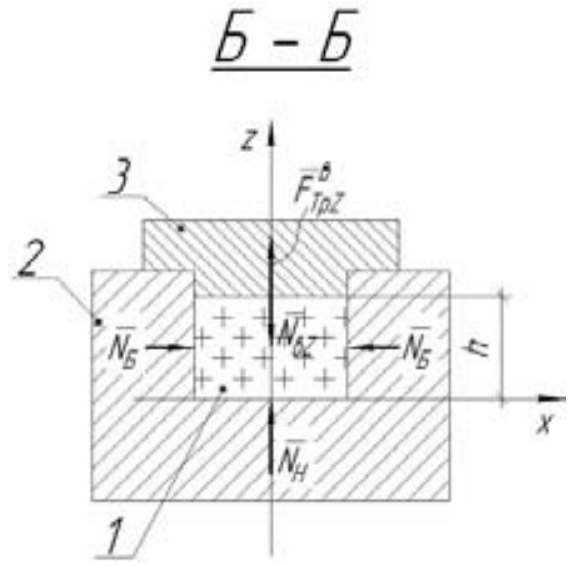

Рис. 3б. Силы, действующие на деформируемый металл в плоскости z0y: 1 - деформируемый металл; 2 - карусельный кристаллизатор; 3 - башмак 
- конец захвата, когда деформируемый металл полностью заполнит поперечное сечение и вступит в полный контакт со стенками канавки и башмака.

Определим условия захвата деформируемого металла наклонной поверхностью башмака под углом во время первого периода захвата. На деформируемый металл со стороны инструмента будут действовать нормальные и касательные силы трения (рис. $3 a$ и б).

Поместим начало координат 0 на границе контакта деформируемый металл и дно канавки в плоскости контакта деформируемого металла с наклонной поверхностью башмака (рис. $3 a$ и б). Для математического моделирования условий захвата рассмотрим условия равновесия заготовки. При этом примем следующие допущения:

1) деформируемый металл - идеальное жесткопластическое тело;

2) башмак и карусельный кристаллизатор несжимаемы

$$
\tau=f_{P} p,
$$

где $f_{P}-$ коэффициент трения; $p$ - нормальное давление.

Из условий равновесия заготовки получим следующую систему уравнений (2):

$$
\left\{\begin{array}{l}
N_{B}\left(\sin \alpha_{5}+f_{5} \cos \alpha_{5}\right)-f_{K}\left(N_{H}+2 N_{5}\right)=0 \\
N_{B}\left(\sin \alpha_{5}+f_{5} \cos \alpha_{5}\right)-f_{K} N_{5}=0 \\
N_{B}\left(f_{5} \sin \alpha_{5}-\cos \alpha_{5}\right)+N_{H}=0 .
\end{array}\right.
$$

Решая данную систему уравнений, получим:

$$
\frac{N_{B} \cos \alpha_{E}}{f_{K}}\left[\operatorname{tg} \alpha_{5}\left(f_{\bar{B}} f_{K}-1\right)-\left(f_{\bar{L}}+f_{K}\right)\right]=0 .
$$

Тогда условия захвата деформируемого металла наклонной поверхностью башмака под углом $\alpha_{b}$ в момент соприкосновения деформируемого металла с башмаком будут следующими:

$$
\frac{f_{5}+f_{K}}{1-f_{5} f_{K}} \geq \operatorname{tg} \alpha_{5}
$$

На рис. 4 показано изменение угла захвата $\alpha_{b}$ от коэффициентов трения на границе контакта между деформируемым металлом и инструментом.

Далее при анализе процесса захвата для последующих периодов, когда происходит смятие кромок заготовки и деформируемый металл полностью заполнит поперечное сечение и вступает в полный контакт со стенками канавки и башмака, т.е. в объеме заготовки и на границе контакта появляется пластическая деформация, примем, что контактное трение отвечает закону Зибеля:

$$
\tau=\mu \sigma_{S}
$$

где $\mu$ - коэффициент трения, $\sigma_{S}-$ сопротивление деформации [3].

Выделим в заготовке, находящейся во входной зоне башмака с углом наклона $\alpha_{b}$, элемент и рассмотрим его равновесие под действием приложенных к нему сил: 


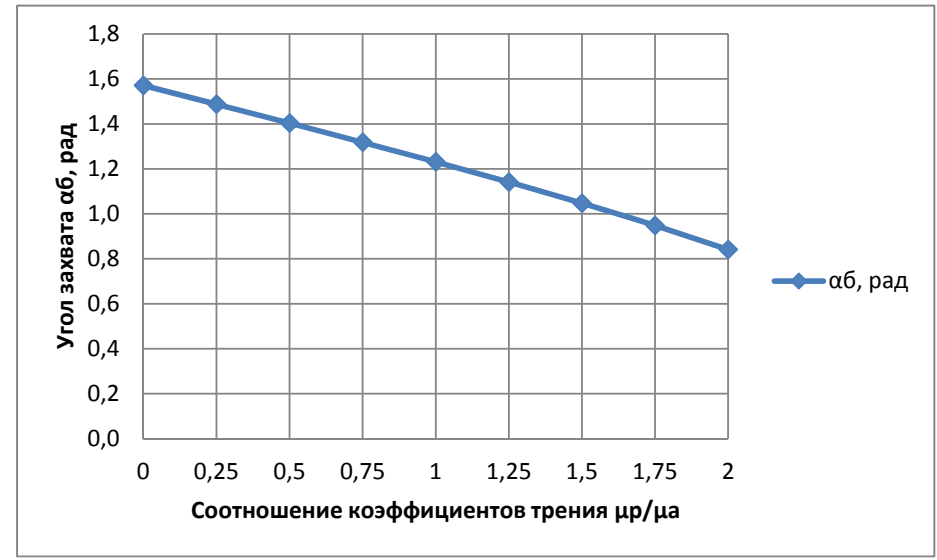

Рис. 4. Изменение угла захвата $\alpha_{5}$ от коэффициентов трения на границе контакта между деформируемым металлом башмаком при $f_{K}=f_{5}$

$$
-(\sigma+d \sigma) h b+\sigma\left(h+R \operatorname{tg} \alpha_{5} \cdot d \varphi\right) b+\tau_{A}(2 R+b) h \cdot d \varphi+\left(\tau_{A}-\frac{\tau_{P}}{\cos \alpha_{5}}\right)\left(R b+\frac{b^{2}}{2}\right) d \varphi=0,
$$

где $h$ и $b$ - высота и ширина кольцевой канавки; $R_{K}$-радиус удаления кольцевой канавки от оси вращения карусельного кристаллизатора; $\tau=\mu_{A} \sigma_{S}$ и $\tau_{P}=\mu_{P} \sigma_{S}-$ активные и реактивные напряжения трения, действующие на границе контакта кольцевой канавки вращающегося карусельного кристаллизатора и деформируемого металла; $\mu_{A}$ и $\mu_{P}$ - коэффициенты трения.

После некоторых преобразований получим

$$
d \sigma=\sigma_{S}\left(\frac{2 R_{K}}{b_{K}}+1\right)\left[\mu_{A}+\frac{b_{K}\left(\mu_{A} \cos \alpha_{B}-\mu_{P}\right)}{2 h_{K} \cos \alpha_{B}}\right] d \varphi
$$

Данное уравнение позволяет оценить изменение напряжений во входной зоне башмака и условия захвата деформируемого металла башмаком в тот момент времени, когда происходит смятие кромок заготовки, т.е. начинается пластическая деформация на границе контакта (рис. 5):

$$
\alpha_{b}<\arccos \frac{\mu_{P}}{\mu_{A}(1+2 h / b)}
$$

Учитывая, что обычно $\mu_{A}=\mu_{P}$, на данном этапе $\alpha_{5}<1,2$ рад, соотношение размеров канавки должно быть следующим: $h>1,1 \cdot b$.

\section{Выводы}

На основании полученных результатов можно сделать следующие выводы: на основе решения уравнений равновесия совмещенного процесса СЛиК с учетом изменения реологических свойств деформируемого металла, конструктивных и технологических параметров получены аналитические зависимости для определения условий захвата процесса СЛиК. В случае несоблюдения данных условий захват металла невозможен, как и сам процесс СЛиК. 


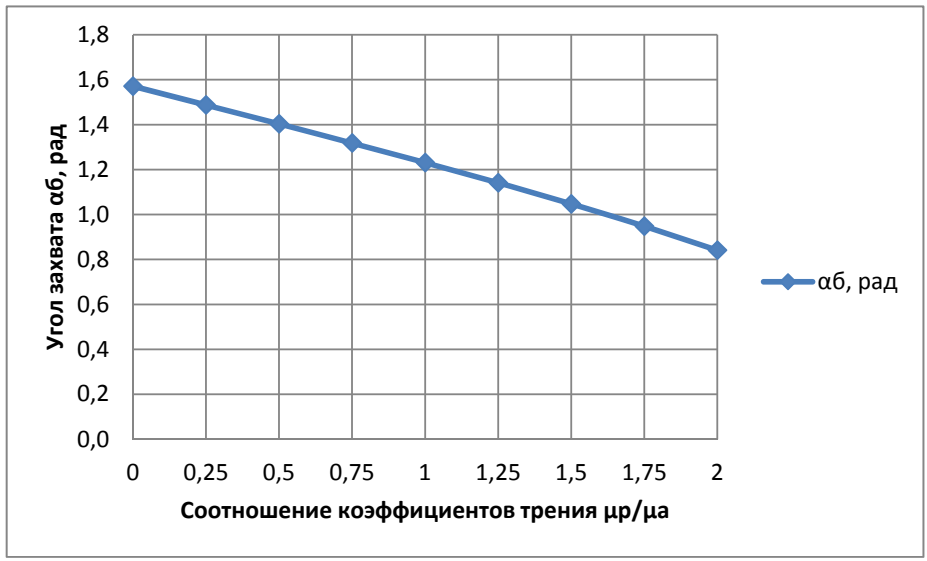

Рис. 5. Изменение угла захвата $\alpha_{5}$ от коэффициентов трения и на границе контакта между деформируемым металлом канавкой кристаллизатора $\mu_{A}$ и башмаком $\mu_{P}$ при высоте $h=10$ мм и ширине $b=10$ мм кольцевой канавки

Работа выполнена при финансовой поддержке КГАУ «Красноярский краевой фонд поддержки научной и научно-технической деятельности» (проект «Разработка инновационной технологии литья - непрерывного прессования сварочной проволоки из алюминиевых сплавов для изготовления волноводов космической техники»).

\section{Список литературы}

[1] Горохов Ю.В. Шеркунов В.Г., Довженко Н.Н. и др. Основы проектирования процессов непрерывного прессования металлов. Красноярск: СФУ, 2013. 268 с.

[2] Горохов Ю.В., Беляев С.В., Шеркунов В.Г. и др. Пат. 119659 РФ / Б. И. 2012. № 24.

[3] Довженко Н.Н., Беляев С.В., Сидельников С.Б. и др. Прессование алюминиевых сплавов: моделирование и управление тепловыми условиями. Красноярск: СФУ, 2009. 256 с. 